\title{
Association Mapping for Drought Tolerance and Yield-Related Traits in Cowpea Accessions
}

\author{
Gabriel V. Nkomo ${ }^{1,2 *}$, Moosa M. Sedibe', Maletsema A. Mofokeng ${ }^{2}$ and Rian Pierneef ${ }^{3}$ \\ ${ }^{1}$ Department of Agriculture Central University of Technology Free State, P Bag X 20539 South \\ Africa 9300; msedibe@cut.ac.za \\ ${ }^{2}$ Agriculture Research Council Grain Crops, P Bag X1251 Potchefstroom, South Africa 2520; \\ MofokengA@arc.agric.za
}

${ }^{3}$ Agriculture Research Council Biotechnology Platform, Pretoria, South Africa; PierneefR@arc.agric.za

*Correspondence:gvnkomo@gmail.com.

The objective of this study were to conduct association mapping for drought tolerance at the seedling stage and yield-related traits. 60 cowpea accessions were used in the study. Singlenucleotide polymorphisms (SNPs) discovered through genotyping by sequencing (GBS) were used for genotyping. Association mapping was conducted using single-marker regression (SMR) in Q Gene, and general linear model (GLM) and mixed linear model (MLM) built in TASSEL. The population of the cowpea accessions were analysed using STRUCTURE 2.3.4 and the peak of delta $\mathrm{K}$ in the greenhouse showed seven population types, whereas the peak of delta $\mathrm{K}$ in the glasshouse indicated the presence of six population types. One SNP marker, $14083649|\mathrm{~F}| 0-9$ was associated with NP with a $p$ value $<0.001$. Fifty SNP markers were associated with PWT at $p<0.001$. Four SNP markers, 14074781|F|0-16, 100047392|F|0-36, $14083801|\mathrm{~F}| 0-28$ and $100051488|\mathrm{~F}| 0-49$ were associated with AVSPD at $p<0.001$. SNP markers, 14074781|F|0-16, 14083801|F|0-28 and 100051488|F|0-49 were associated with PL at $\mathrm{P}<0.001$. Five SNP markers, 100047392|F|0-36, 14083801|F|0-28, 100072738|F|0-34, 14076881|F|0-49 and 14076881|F|0-49 were associated with PWDTH at $p<0.001$. The 65 SNP markers identified can be used in cowpea molecular breeding to select for AVSPD, NP, PL, PWDTH, PWT, and RR through marker assisted selection (MAS).

Key words: Association mapping, chromosomes, drought tolerance, markers, structure, traits.

\section{Introduction}

Cowpea [Vigna unguiculata (L.) Walp.] is a food legume of the family Fabaceae/Papilionaceae (1). According to (2), all cultivated cowpeas are grouped under the species Vigna unguiculata, which is subdivided into four cultivar groups: Unguiculata (common cowpea for food and fodder), Biflora (catjang), Sesquipedalis (yard long or asparagus bean used as a vegetable), and 
Textilis (used for fibres). The crop is of major importance to many smallholder farmers in Africa and the developing world, as it serves as food, cash crop, animal feed, and manure (3).

The major aims of cowpea breeding are high yield, early maturity for grain production, long vegetative period for vegetable production, high leaf and grain nutrient contents, high cooking quality, and high emergence rate. In order to provide farmers with quality seeds of improved cultivars, breeding programmes and seed systems should be based on information on the genetic diversity available in the germplasm (4). According to (5), assessments of phenotypic or genotypic diversity in cultivated plants provide useful information for the improvement of germplasm collections, which provide material for genetic improvement and breeding.

Studies of association mapping for drought tolerance in cowpea using DArTSeq genotyping data are very limited. Drought is a major production constraint in the smallholder farming sector in Zimbabwe; thus, there is a need to develop drought-tolerant varieties, which in turn requires the identification of genotypes that carry genes associated with drought tolerance. Association mapping was used to investigate the associations among 76 SSR markers and six drought-related traits on a set of 107 barley accessions evaluated under well-watered and drought-stress conditions (6). The results showed that there were 36 significant marker-trait associations for drought-related traits.(7), used single nucleotide polymorphisms (SNP) associated with drought tolerance indices in 328 wheat lines using a genome-wide association study (GWAS) under fully irrigated and rain-fed conditions. Results showed that most associations were located on chromosome $4 \mathrm{~A}$, and that this chromosome is very important in drought tolerance and should be used in wheat improvement programmes. 
In a study of correlation coefficient and path analysis in the cowpea germplasm line, (2), observed significant and positive correlations between the growth characters and seed yield of cowpea. Using a path analysis study, the experiment further concluded that seed yield in cowpea can be improved by focusing on the traits of biological yield per plant, harvest index, number of pods per plant, and plant height. (8), studied phenotypic and genotypic divergence for yield and related quantitative traits among 30 cowpea landraces in Cameroon. The study revealed strong correlations between seed length and grain yield, 100-seed weight and grain yield, 100-seed weight and seed length, number of seeds per pod and pod length, number of branches per plant and plant biomass, and grain yield and leaf width. Thus, characters such as seed length or 100-seed weight are very useful in early selection when improving yield.

(9), evaluated the genetic variability among 20 wild cowpea accessions and observed high morphological variability among the accessions. The high variability observed among the wild cowpea accessions in terms of their agro-morphological and yield parameters provided useful traits in the crop that can be exploited for its improvement. Results obtained from (10), on population structure analysis and association mapping of the seed antioxidant content in the 369-accession USDA cowpea [Vigna unguiculata (L.) Walp.] core collection using SNPs show that there were significant correlations between the seed antioxidant content and black seed colour. It was further observed and concluded that cowpea accessions with red and black seed coat colours were useful as parents in cowpea breeding programmes to provide new cowpea cultivars with high seed antioxidant contents.

(11), analysed the genomic regions, cellular constituents and genes controlling pod length variation in cowpeas. The research observed that cell proliferation was the major reason for extended pods as against cell elongation or enlargement. A total of 116 and 155 cowpea accessions during emergence and seedling stages, respectively were analysed for salt 
tolerance index with 1,049 single nucleotide polymorphisms (SNPs) that were used for association analysis (12). A total of three SNPs, Scaffold 87490_622, Scaffold87490_630, and C35017374_128, were highly associated with salt tolerance during germination stage while seven SNPs, Scaffold93827_270, Scaffold68489_600, Scaffold87490_633, Scaffold87490_640, Scaffold82042_3387, C35069468_1916, and Scaffold93942_1089, were associated to salt tolerance at the seedling stage. Thus, these SNP markers could be used as a tool to select salt-tolerant lines for breeding improved salt-tolerant cowpea cultivars.

The objective of this study were to conduct association mapping for drought tolerance at the seedling stage and yield-related traits in cowpea.

\section{Materials and Methods}

\section{Phenotype data}

A total of 60 cowpea accessions collected from three geographic origins were used in this study (Table 1). Of these, 33 accessions were from the International Institute of Tropical Agriculture (IITA) in Nigeria, 19 were from the Agricultural Research Council - Grain Crops in South Africa, and eight were from smallholder farmers in Buhera District in Zimbabwe.

The seeds used were grown under favourable conditions in two screen houses (glasshouse and greenhouse). All of the populations phenotyped were grown in greenhouse and glasshouse trials. The cowpea accessions were planted in pots in topsoil mixed with compost (3:1) at the Agriculture Research Council - Grain Crops, Potchefstroom, South Africa in January 2019 for the greenhouse trial and February 2019 for the glasshouse trial. A triplicated $6 \times 10$ alpha lattice design was used for the experiment. In all greenhouse and glasshouse trials, mature pods were harvested and dried for storage ( $<15 \%$ moisture) after screening for drought tolerance. Seeds were subsequently cleaned from the pods, counted, and weighed. 
Table S1: List of cowpea accessions used in this study obtained from three geographic origin.

\begin{tabular}{|c|c|c|c|}
\hline Entry & Name & Source & Origin \\
\hline 1 & Dr Saunders & ARC-GC & South Africa \\
\hline 2 & IT96D-610 & IITA & Nigeria \\
\hline 3 & RV 574 & ARC-GC & South Africa \\
\hline 4 & RV 342 & ARC-GC & South Africa \\
\hline 5 & Pan 311 & ARC-GC & South Africa \\
\hline 6 & Bechuana white & ARC-GC & South Africa \\
\hline 7 & Barapara jena & Buhera & Zimbabwe \\
\hline 8 & TVU 9443 & IITA & Nigeria \\
\hline 9 & $95 \mathrm{~K}-589-2$ & IITA & Nigeria \\
\hline 10 & RV 344 & ARC-GC & South Africa \\
\hline 11 & Agrinawa & ARC-GC & South Africa \\
\hline 12 & IT 95K-207-15 & IITA & Nigeria \\
\hline 13 & Orelo & IITA & Nigeria \\
\hline 14 & TVU 9671 & IITA & Nigeria \\
\hline 15 & Mutonono & Buhera & Zimbabwe \\
\hline 16 & UAM-14-143-4-1 & IITA & Nigeria \\
\hline 17 & $98 \mathrm{~K}-503-1$ & IITA & Nigeria \\
\hline 18 & RV 503 & ARC-GC & South Africa \\
\hline 19 & 86 D 1010 & IITA & Nigeria \\
\hline 20 & TVU 9620 & IITA & Nigeria \\
\hline 21 & RV 202 & ARC-GC & South Africa \\
\hline 22 & RV 351 & ARC-GC & South Africa \\
\hline 23 & Encore & ARC-GC & South Africa \\
\hline 24 & TVU 14190 & IITA & Nigeria \\
\hline 25 & IT $89 \mathrm{KD}-288$ & IITA & Nigeria \\
\hline 26 & RV 551 & ARC-GC & South Africa \\
\hline 27 & IT 82E-18 & IITA & Nigeria \\
\hline 28 & Barapara purple & Buhera & Zimbabwe \\
\hline 29 & Kangorongondo & Buhera & Zimbabwe \\
\hline 30 & $835-911$ & IITA & Nigeria \\
\hline 31 & ITOOK 76 & IITA & Nigeria \\
\hline 32 & $98 \mathrm{~K}-476-8$ & IITA & Nigeria \\
\hline 33 & Ziso dema & Buhera & Zimbabwe \\
\hline 34 & Chibundi mavara & Buhera & Zimbabwe \\
\hline 35 & $90 \mathrm{~K}-284-2$ & IITA & Nigeria \\
\hline 36 & RV 221 & ARC-GC & South Africa \\
\hline 37 & RV 343 & ARC-GC & South Africa \\
\hline 38 & IT 98K-506-1 & IITA & Nigeria \\
\hline 39 & Oleyin & IITA & Nigeria \\
\hline 40 & IT 07-292-10 & IITA & Nigeria \\
\hline 41 & IT $08 \mathrm{~K}-150-27$ & IITA & Nigeria \\
\hline 42 & RV500 & ARC-GC & South Africa \\
\hline 43 & IT 90K-277-2 & IITA & Nigeria \\
\hline 44 & 98D-1399 & IITA & Nigeria \\
\hline 45 & ITOOK 1263 & IITA & Nigeria \\
\hline 46 & RV 563 & ARC-GC & South Africa \\
\hline 47 & IT 18 & Buhera & Zimbabwe \\
\hline 48 & RV 194 & ARC-GC & South Africa \\
\hline 49 & $335-95$ & IITA & Nigeria \\
\hline 50 & TVU 12746 & IITA & Nigeria \\
\hline 51 & IT 07-274-2-9 & IITA & Nigeria \\
\hline 52 & $97 \mathrm{~K}-499-35$ & IITA & Nigeria \\
\hline 53 & IT 07-318-33 & IITA & Nigeria \\
\hline 54 & IT89-KD-288 & IITA & Nigeria \\
\hline 55 & RV558 & ARC-GC & South Africa \\
\hline 56 & IT 99K-573-2-1 & IITA & Nigeria \\
\hline 57 & Mupengo dema & Buhera & Zimbabwe \\
\hline 58 & $\mathrm{CH} 47$ & ARC-GC & South Africa \\
\hline 59 & TVU 13004 & IITA & Nigeria \\
\hline 60 & IT 90K-59 & IITA & Nigeria \\
\hline
\end{tabular}

IITA-International Institute of Tropical Agriculture; ARC GC-Agriculture Research Council Grain 


\section{DNA extraction, sequencing, and SNP calling}

DNA extractions and sequencing were performed using the DArTseq protocol (Diversity Arrays Technology Pty Ltd., Canberra, Australia). About $1 \mathrm{~g}$ of young leaf tissue from each accession was used for genomic DNA extraction. Genomic DNA was isolated from the frozen leaves using a modified cetyltrimethyl ammonium bromide (CTAB)/chloroform/ isoamyl alcohol method (13). The frozen leaf tissue was ground and mixed with $2 \%$ pre-warmed $\left(60{ }^{\circ} \mathrm{C}\right) \mathrm{CTAB}$ isolation buffer of $1.4 \mathrm{M} \mathrm{NaCl}, 100 \mathrm{mM}$ Tris $(\mathrm{pH} 8.0)$, and $20 \mathrm{mM}$ EDTA (Sigma, Saint Louis, USA). The mixture was then transferred to a $2 \mathrm{ml}$ microcentrifuge tube and incubated at $60{ }^{\circ} \mathrm{C}$ for $1 \mathrm{~h}$. DNA was extracted once with chloroform--isoamyl alcohol (Chl/IAA; 24:1) (Sigma, Saint Louis, USA) and precipitated with two volumes of isopropanol. The obtained pellet was washed with $70 \% \mathrm{EtOH}$, dried, and dissolved in $100 \mu \mathrm{l}$ of TE buffer with $50 \mu \mathrm{g} / \mathrm{ml}$ RNase A (Sigma, Saint Louis, USA). The extracted DNA was quantified by $0.8 \%$ agarose gel electrophoresis, and was adjusted to $50 \mathrm{ng} / \mu \mathrm{l}$ for DArT and SNP genotyping. GBS was done using Illumina HiSEq2000 at the Biosciences eastern and central Africa (BecA)-ILRI, Kenya. SNP calling were performed for all tags from all libraries enclosed within the DArTsoft14 analysis clustered using DArT PL's $\mathrm{C}^{++}$algorithm program at a brink distance of three. Parsing of the clusters into separate SNP loci was performed using a technique called balance of read counts for the allelic pairs. Additional choice criteria were further added to the algorithm program supported by an analysis of roughly 1,000 controlled cross populations. Testing for deviations from the Hardy-Weinberg equilibrium of alleles in these populations was conducted to facilitate the selection of technical parameters to effectively discriminate true allelic variants from paralogous sequences. In addition, multiple samples were processed from DNA to allelic calls as technical replicates, and scoring consistency was used as the main selection criteria for high-quality/low-error rate markers. Calling quality was assured by a high 
average browse depth per locus (average across all markers was over 30 reads/locus). DNA was diluted to $50 \mathrm{ng} / \mu \mathrm{l}$ for GBS analysis.

\section{Data Analysis}

\section{Population structure analysis}

The population structure of the cowpea accessions evaluated for growth traits was inferred using STRUCTURE 2.3.4 (14). Population structure (K) was analysed with an admixture model with a correlated allele frequency model, which was independent for each run. The identification of the delta $\mathrm{K}$ values and optimal $\mathrm{K}$, based on the formula devised by (15). The formula allowed a reliable screening of appropriate $\mathrm{K}$ values using Structure Harvester (http://taylor0.biology.ucla.edu/structureHarvester/; 16). A Q-matrix and K vectors were established shortly after the optimal $\mathrm{K}$ was computed. The Q-matrix was used for association analysis studies in TASSEL (Trait Analysis by Association Evolution and Linkage) (17).

\section{Association analysis}

SNP genotype data generated by genotype by sequencing (GBS) was first filtered to remove the monomorphic SNP sites. Report_DCpe18-2608_SNP_singlerow_2.csv was converted to vcf format using matk. The vcf file was filtered using vcf tools. The vcf format was then converted to plink files using vcf tools. Marker-trait association analysis was evaluated using using plink. Analysis in R software was done using the following packages; vcfR, poppr, ape and qqman. Significantly associated SNP markers with traits were identified at $p<0.001$ (17).

\section{Results}

The population of the cowpea accessions were analysed using STRUCTURE 2.3.4 and the peak of delta $\mathrm{K}$ in the greenhouse (A) was $\mathrm{K}=7$, highlighting seven population types, whereas 
in the glasshouse (B), the peak of delta $K$ was $K=6$, indicating the presence of six population types (Figure 1).

A

\section{green_fast}

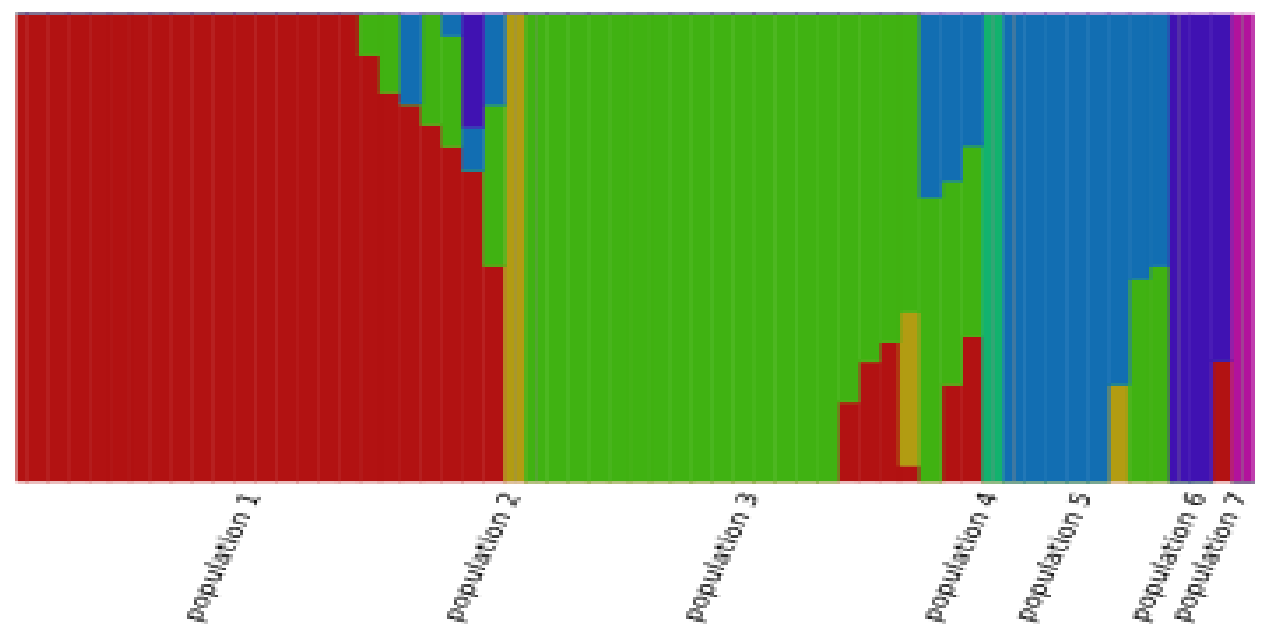

B

\section{glass_fast}

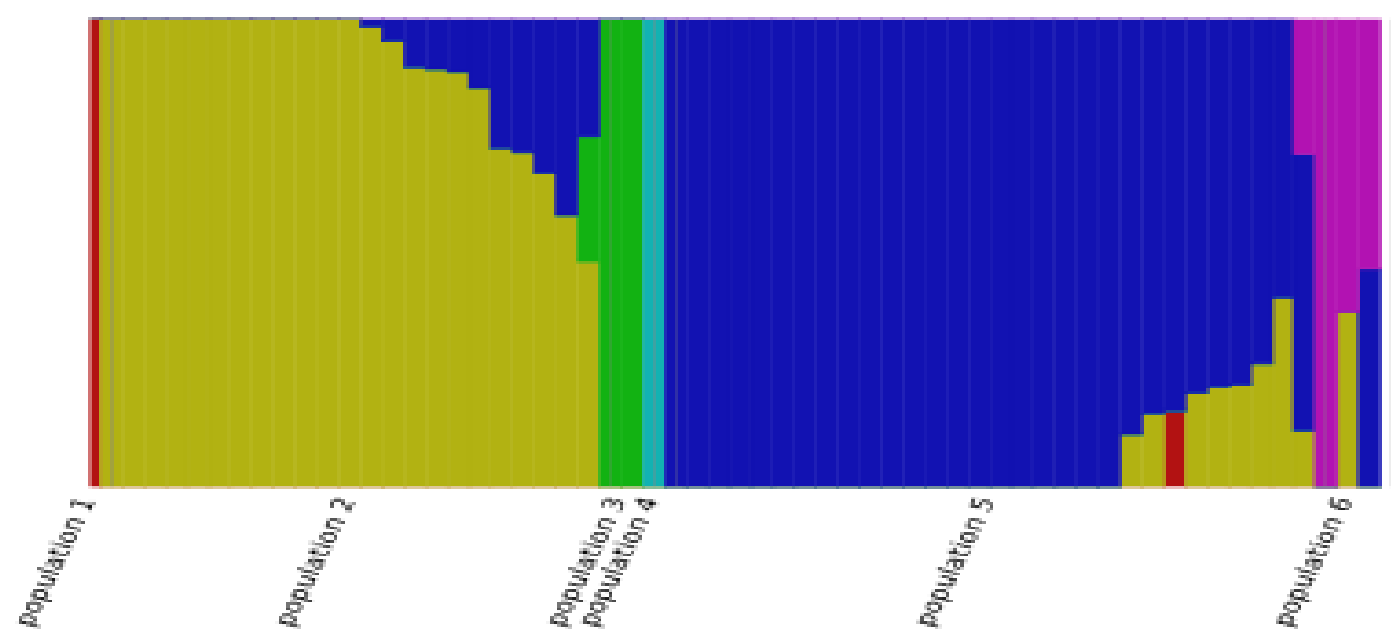

Figure1: Classification of 60 cowpea accessions into seven populations in greenhouse (A) and six populations in glasshouse (B) using STRUCTURE Version 2.3.4 


\section{Association Analysis}

SNP markers were identified for number of pods, recovery rate, pod weight, average seeds per pod, pod length and pod width. Two SNP markers, 14083649|F|0-9 and 100100635|F|053 were associated with number of pods (NP) with a $p$ value $<0.001$ (Table 2). The significant markers occurred on chromosome 10. SNP marker 100100635|F|0-53 contributed $43 \%$ of the phenotypic variation.SNP marker $100084158|\mathrm{~F}| 0-6$ was associated with recovery rate $(\mathrm{RR})$ at $p<0.001$ and was positioned at chromosome 10 while $\mathrm{R}^{2}$ was at $10 \%$. (Table 2).

Fifty SNP markers were associated with pod weight (PWT) at $p<0.001$ (Table 2). Out of these, 10 SNPs were on chromosome one, one SNP on chromosome two, six SNPs on chromosome three, four SNPs chromosome five, five SNPs on chromosome six, nine SNPs on chromosome seven, seven SNPs on chromosome eight, two SNPs on chromosome nine, six SNPs on chromosome 10 and four SNPs on chromosome 11. SNP marker 100051258|F|0-67on chromosome nine contributed $53 \%$ of variation followed by chromosomes seven and nine which accounted for $52 \%$ of the variation. SNPs on chromosome one accounted for $35 \%$ of phenotypic variation at PWT.

Four SNP markers, $14074781|\mathrm{~F}| 0-16, \quad 100047392|\mathrm{~F}| 0-36, \quad 14083801|\mathrm{~F}| 0-28$ and $100051488|\mathrm{~F}| 0-49$ were associated with average seeds per pod (AVSPD) at $p<0.001$. All these SNPs were positioned at chromosome 3 (Table 2). SNP marker 14083801|F|0-28 had the highest $\mathrm{R}^{2}$ at 35\%. SNP markers, 14074781|F|0-16, 14083801|F|0-28 and 100051488|F|0-49 were associated with pod length (PL) at $p<0.001$. These SNPs were all positioned on chromosome 3 while SNP marker 14083801|F|0-28 explained $34 \%$ of phenotypic variation for PL. Four SNP markers, 100047392|F|0-36, 14083801|F|0-28, 100072738|F|0-34 and 14076881|F|0-49 were associated with pod width (PWDTH) at $p<0.001$. These were all on 
chromosome 3 while marker $14083801|\mathrm{~F}| 0-28$ accounted for $32 \%$ of phenotypic variation for PWDTH. Most of these markers were distributed on chromosomes 3 (17markers), chromosome 1(10 markers) and chromosome 7(9 makers). 
Table 2 List of markers associated with NP, RR, PWT, AVSPD, PL and PWDTH

\begin{tabular}{|c|c|c|c|c|c|c|}
\hline Trait & CHR & SNP & BP & SE & $\mathbf{R}^{2}$ & $\mathbf{P}$ \\
\hline PWT & 1 & $100053502|\mathrm{~F}| 0-62$ & 1251569 & 12.4 & 0.3596 & $2.628 \mathrm{e}-06$ \\
\hline PWT & 1 & $14078204|\mathrm{~F}| 0-43$ & 1292063 & 11.75 & 0.3556 & $6.238 \mathrm{e}-07$ \\
\hline PWT & 1 & $100044718|\mathrm{~F}| 0-57$ & 1432640 & 12.36 & 0.3552 & $2.501 \mathrm{e}-06$ \\
\hline PWT & 1 & $100046227|\mathrm{~F}| 0-46$ & 1557122 & 11.75 & 0.3556 & $6.238 \mathrm{e}-07$ \\
\hline PWT & 1 & $100063465|\mathrm{~F}| 0-35$ & 1557915 & 11.85 & 0.3554 & $7.901 \mathrm{e}-07$ \\
\hline PWT & 1 & $100072600|\mathrm{~F}| 0-25$ & 1564066 & 11.75 & 0.3556 & $6.238 \mathrm{e}-07$ \\
\hline PWT & 1 & $100071153|\mathrm{~F}| 0-66$ & 1564132 & 12.16 & 0.3557 & $1.545 \mathrm{e}-06$ \\
\hline PWT & 1 & $100048141|\mathrm{~F}| 0-63$ & 1694886 & 11.75 & 0.3556 & $6.238 \mathrm{e}-07$ \\
\hline PWT & 1 & $100044957|\mathrm{~F}| 0-63$ & 3528678 & 12.06 & 0.3553 & $1.253 \mathrm{e}-06$ \\
\hline PWT & 1 & $100063872|\mathrm{~F}| 0-10$ & 28798986 & 11.75 & 0.3556 & $6.238 \mathrm{e}-07$ \\
\hline PWT & 2 & $100096611|\mathrm{~F}| 0-40$ & 15499573 & 11.75 & 0.3556 & $6.238 \mathrm{e}-07$ \\
\hline PWT & 3 & $100054066|\mathrm{~F}| 0-68$ & 14331695 & 12.38 & 0.3561 & $2.41 \mathrm{e}-06$ \\
\hline PWT & 3 & $100051321|\mathrm{~F}| 0-47$ & 53345546 & 7.327 & 0.2522 & $5.913 \mathrm{e}-05$ \\
\hline PWT & 5 & $100053097|\mathrm{~F}| 0-7$ & 16393146 & 12.04 & 0.3553 & $1.253 \mathrm{e}-06$ \\
\hline PWT & 5 & $100075598|\mathrm{~F}| 0-66$ & 16791034 & 9.149 & 0.2048 & 0.0003197 \\
\hline PWT & 5 & $14058797|\mathrm{~F}| 0-67$ & 25444199 & 2.974 & 0.3953 & $1.63 e-07$ \\
\hline $\mathbf{R R}$ & 5 & $100084158|\mathrm{~F}| 0-6$ & 4031158 & 5.219 & 0.2196 & 0.0004587 \\
\hline PWT & 6 & $100070503|\mathrm{~F}| 0-16$ & 13371481 & 12.86 & 0.3553 & $6.216 \mathrm{e}-06$ \\
\hline PWT & 6 & $100045443|\mathrm{~F}| 0-35$ & 18431456 & 9.476 & 0.1759 & 0.0009464 \\
\hline PWT & 6 & $100050903|\mathrm{~F}| 0-29$ & 18751348 & 11.75 & 0.3556 & $6.238 \mathrm{e}-07$ \\
\hline PWT & 6 & $100049686|\mathrm{~F}| 0-66$ & 18764966 & 11.97 & 0.3693 & $1.096 \mathrm{e}-06$ \\
\hline PWT & 6 & $100087696|\mathrm{~F}| 0-41$ & 26017102 & 9.135 & 0.2341 & 0.0001035 \\
\hline PWT & 7 & $100047575|\mathrm{~F}| 0-22$ & 823054 & 10.04 & 0.5293 & $6.718 \mathrm{e}-11$ \\
\hline PWT & 7 & $100071982|\mathrm{~F}| 0-68$ & 3037310 & 10.3 & 0.5293 & $2.13 \mathrm{e}-10$ \\
\hline PWT & 7 & $14079990|\mathrm{~F}| 0-24$ & 31169450 & 5.395 & 0.2547 & $4.587 \mathrm{e}-05$ \\
\hline PWT & 7 & $100083914|\mathrm{~F}| 0-58$ & 32980963 & 10.04 & 0.5293 & $6.718 \mathrm{e}-11$ \\
\hline PWT & 7 & $100076974|\mathrm{~F}| 0-16$ & 32991155 & 10.46 & 0.5301 & $4.413 \mathrm{e}-10$ \\
\hline PWT & 7 & $100052969|\mathrm{~F}| 0-35$ & 33021922 & 10.27 & 0.5299 & $2.056 \mathrm{e}-10$ \\
\hline PWT & 7 & $14084025|\mathrm{~F}| 0-9$ & 33082576 & 6.857 & 0.1979 & 0.0009514 \\
\hline PWT & 7 & $100084809|\mathrm{~F}| 0-62$ & 38432224 & 11.84 & 0.3556 & $7.851 \mathrm{e}-07$ \\
\hline PWT & 7 & $100073645|\mathrm{~F}| 0-45$ & 38481917 & 11.75 & 0.3556 & $6.238 \mathrm{e}-07$ \\
\hline PWT & 8 & $100052927|\mathrm{~F}| 0-48$ & 752816 & 10.19 & 0.5297 & $1.416 \mathrm{e}-10$ \\
\hline PWT & 8 & $100073137|\mathrm{~F}| 0-62$ & 29029951 & 9.106 & 0.3003 & $2.613 \mathrm{e}-05$ \\
\hline PWT & 8 & ${ }_{14087242|\mathrm{~F}| 0-6}$ & 34660664 & 5.361 & 0.3628 & $1.146 \mathrm{e}-06$ \\
\hline PWT & 8 & $14084814|\mathrm{~F}| 0-10$ & 34681513 & 2.758 & 0.3511 & $9.587 \mathrm{e}-07$ \\
\hline PWT & 8 & $100073582|\mathrm{~F}| 0-29$ & 35713044 & 10.44 & 0.5304 & $4.336 \mathrm{e}-10$ \\
\hline PWT & 8 & $100044312|\mathrm{~F}| 0-24$ & 35970502 & 10.19 & 0.5297 & $1.416 \mathrm{e}-10$ \\
\hline PWT & 8 & $100072423|\mathrm{~F}| 0-62$ & 36066768 & 10.04 & 0.5293 & $6.718 \mathrm{e}-11$ \\
\hline PWT & 9 & $100051258|\mathrm{~F}| 0-67$ & 7118132 & 10.35 & 0.5322 & $2.657 \mathrm{e}-10$ \\
\hline PWT & 9 & $100044652|\mathrm{~F}| 0-17$ & 12400903 & 4.727 & 0.1955 & 0.0008148 \\
\hline PWT & 10 & $100045290|\mathrm{~F}| 0-13$ & 5588111 & 7.555 & 0.2036 & 0.0003779 \\
\hline PWT & 10 & $100097542|\mathrm{~F}| 0-53$ & 15068089 & 10.21 & 0.5295 & $1.436 \mathrm{e}-10$ \\
\hline PWT & 10 & $100047842|\mathrm{~F}| 0-31$ & 34051300 & 7.633 & 0.1744 & 0.0009977 \\
\hline PWT & 10 & $100049329|\mathrm{~F}| 0-68$ & 39976951 & 9.453 & 0.206 & 0.0005005 \\
\hline NP & 10 & $100100635|\mathrm{~F}| 0-53$ & 27320523 & 2.221 & 0.4324 & $2.127 \mathrm{e}-07$ \\
\hline NP & 10 & 14083649|F|0-9 & 33863660 & 0.3972 & 0.1804 & 0.0008001 \\
\hline PWT & 11 & $100087702|\mathrm{~F}| 0-13$ & 1176941 & 6.47 & 0.2047 & 0.0003207 \\
\hline PWT & 11 & $100051586|\mathrm{~F}| 0-57$ & 1200317 & 8.605 & 0.2965 & $8.249 \mathrm{e}-06$ \\
\hline PWT & 11 & $100081173|\mathrm{~F}| 0-34$ & 40185748 & 9.476 & 0.1759 & 0.0009464 \\
\hline PWT & 11 & 100049496|F|0-26 & 40225628 & 9.476 & 0.1759 & 0.0009464 \\
\hline AVPSD & 3 & $14074781|\mathrm{~F}| 0-16$ & 56268741 & 0.7032 & 0.1906 & 0.0006128 \\
\hline AVPSD & 3 & $100047392|\mathrm{~F}| 0-36$ & 59016170 & 0.6695 & 0.1902 & 0.0009797 \\
\hline AVPSD & 3 & $14083801|\mathrm{~F}| 0-28$ & 59879328 & 0.5533 & 0.3582 & $5.547 \mathrm{e}-07$ \\
\hline AVPSD & 3 & $100051488|\mathrm{~F}| 0-49$ & 63223396 & 1.078 & 0.2163 & 0.0006666 \\
\hline PL & 3 & $14074781|\mathrm{~F}| 0-16$ & 56268741 & 0.9575 & 0.2103 & 0.0002943 \\
\hline PL & 3 & $14083801|\mathrm{~F}| 0-28$ & 59879328 & 0.7713 & 0.3438 & $1.061 \mathrm{e}-06$ \\
\hline PL & 3 & $100051488|\mathrm{~F}| 0-49$ & 63223396 & 1.438 & 0.2356 & 0.0003527 \\
\hline PWDTH & 3 & $100047392|\mathrm{~F}| 0-36$ & 59016170 & 0.07287 & 0.2176 & 0.0003776 \\
\hline PWDTH & 3 & $14083801|\mathrm{~F}| 0-28$ & 59879328 & 0.06198 & 0.3203 & $2.995 \mathrm{e}-06$ \\
\hline PWDTH & 3 & $100072738|\mathrm{~F}| 0-34$ & 60195503 & 0.07753 & 0.1939 & 0.0008615 \\
\hline PWDTH & 3 & $14076881|\mathrm{~F}| 0-49$ & 60200022 & 0.07288 & 0.2043 & 0.0003264 \\
\hline PWT & 3 & $100050332|\mathrm{~F}| 0-42$ & 6019724 & 4.405 & 0.1964 & 0.0004401 \\
\hline PWT & 3 & $100071756|\mathrm{~F}| 0-66$ & 53358047 & 4.53 & 0.1974 & 0.0006774 \\
\hline PWT & 3 & 14083801|F|0-28 & 59879328 & 0.9134 & 0.3088 & $4.899 \mathrm{e}-06$ \\
\hline PWT & 3 & $100047389|\mathrm{~F}| 0-39$ & 60895529 & 1.006 & 0.2022 & 0.0003529 \\
\hline
\end{tabular}


Association mapping was performed using rrBLUP to identify loci linked to the evaluated traits. Significant SNPs were compared to those that passed a significance threshold of $\log _{10}(p)>5$ ] in TASSEL 5.0 analysis. Figure 2 highlights the association in glasshouse experiment on the number of pods (NP), recovery rate (RR), and pod weight (PWT).

The average seeds per pod (AVSPD), pod length (PL), pod width (PWDTH) and pod weight (PWT) had were significantly associated in the greenhouse experiment (Figure 3).

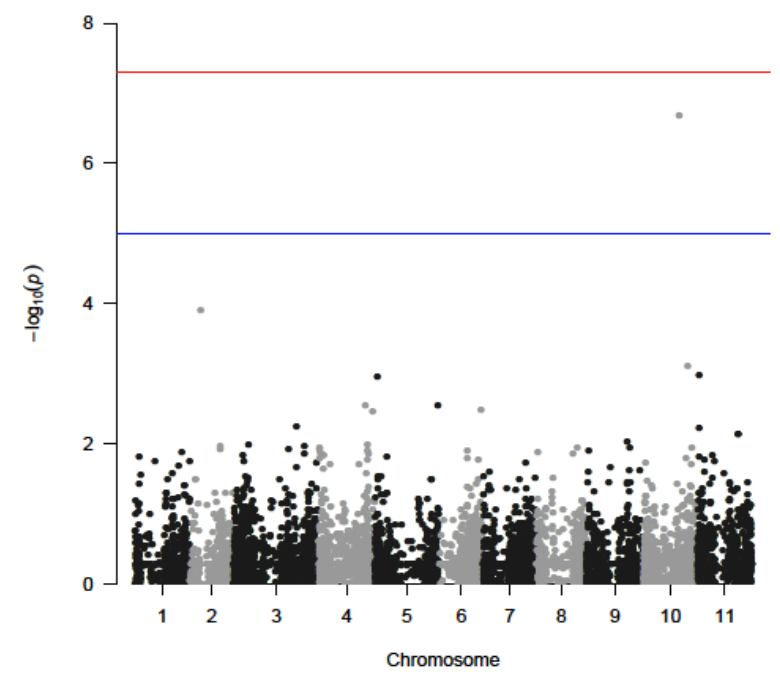

a

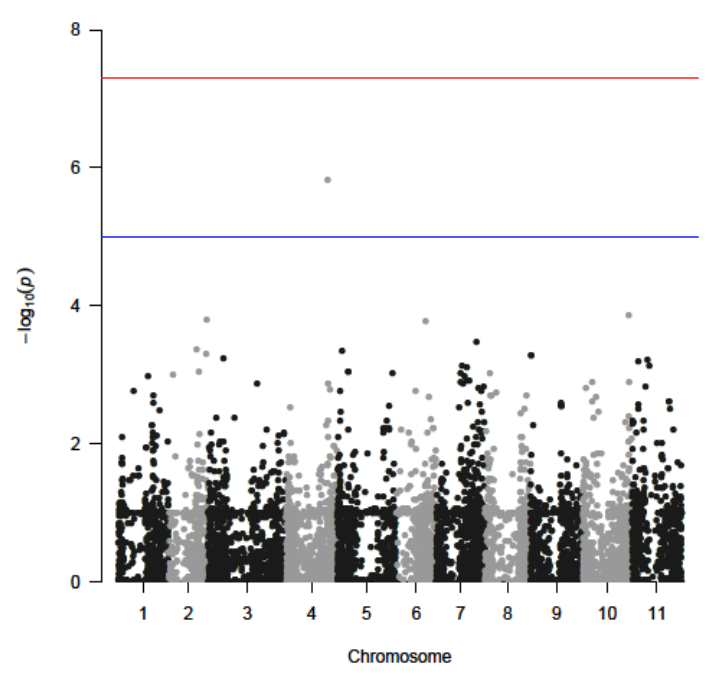

b

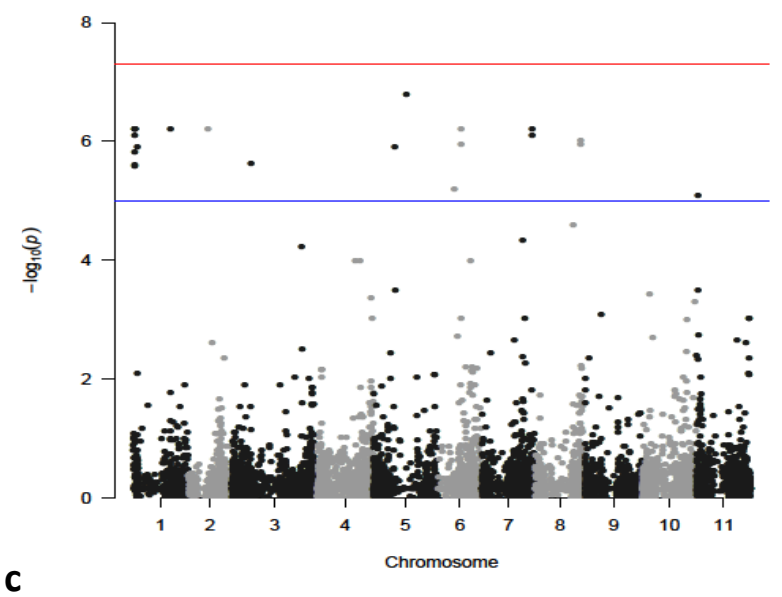

Figure 2: Association mapping results for wilting and yield related traits in 60 cowpea accession in glasshouse. Manhattan plots from association mapping using mixed linear model. $\mathrm{X}$-axis shows the SNPs along the 11 chromosomes of cowpea accessions and $\mathrm{Y}$-axis shows $\log _{10}$ (p) value of association for each SNP. The solid horizontal blue line indicates the calculated threshold value for declaring a significant association. The red line indicates the 
significance threshold (FDR $<0.005)$. a. NP, number of pods; b. RR, recovery rate; c. PWT, pod weight
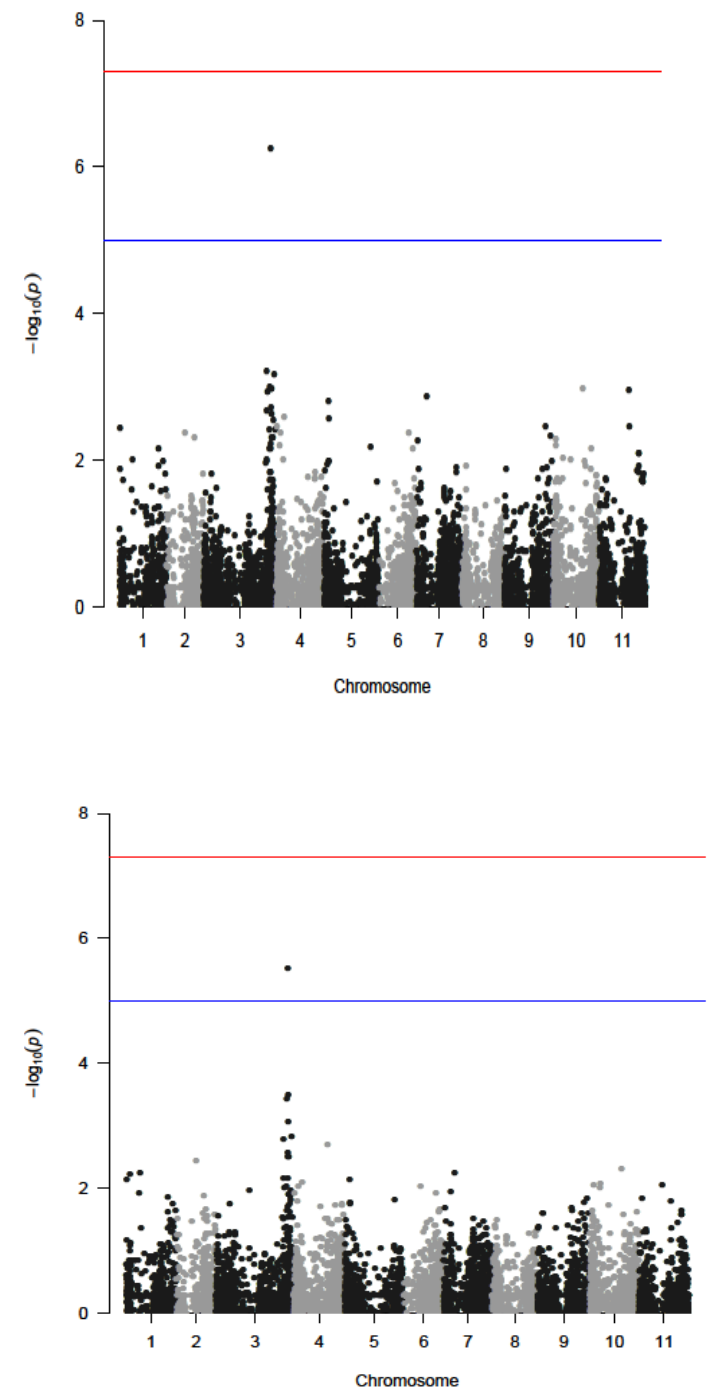

c

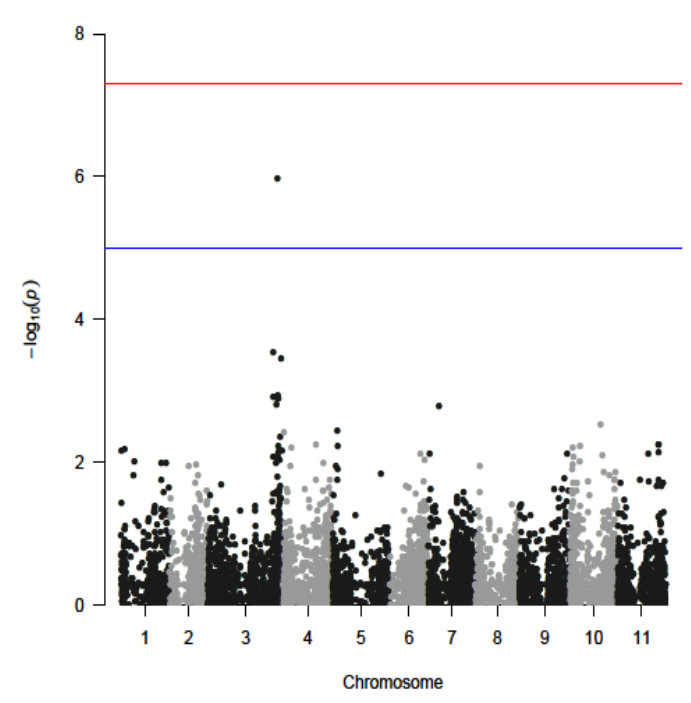

b

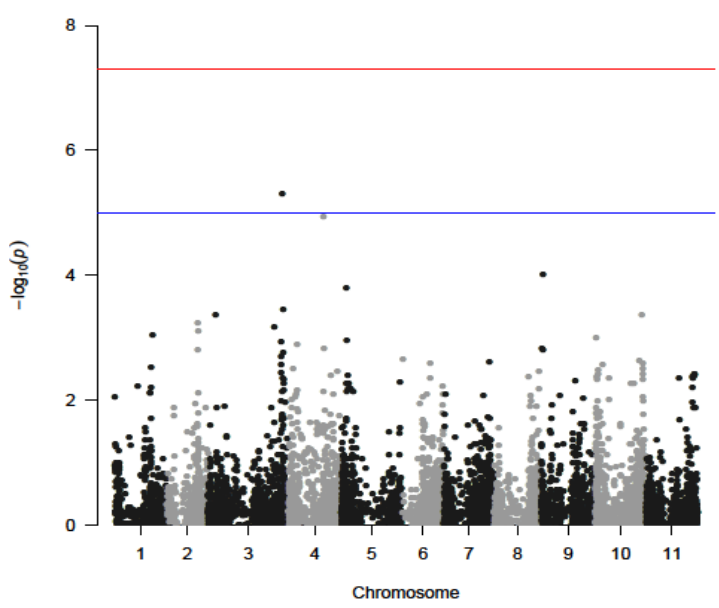

d

Figure 3: Association mapping results for wilting and yield related traits in 60 cowpea accession in greenhouse. Manhattan plots from association mapping using mixed linear model. X-axis shows the SNPs along the 11 chromosomes of cowpea accessions and Y-axis shows $-\log _{10}(\mathrm{p})$ value of association for each SNP. The solid horizontal blue line indicates the calculated threshold value for declaring a significant association.

a. Average seeds per pod, AVSPD; b. pod length, PL; c. pod width, PWDTH; d. pod weight, PWT 


\section{Population-trait associations}

The quantile-quantile (QQ) plots in Figures 3 and 4 show the level of association mapping in both the glasshouse and greenhouse experiments, respectively.

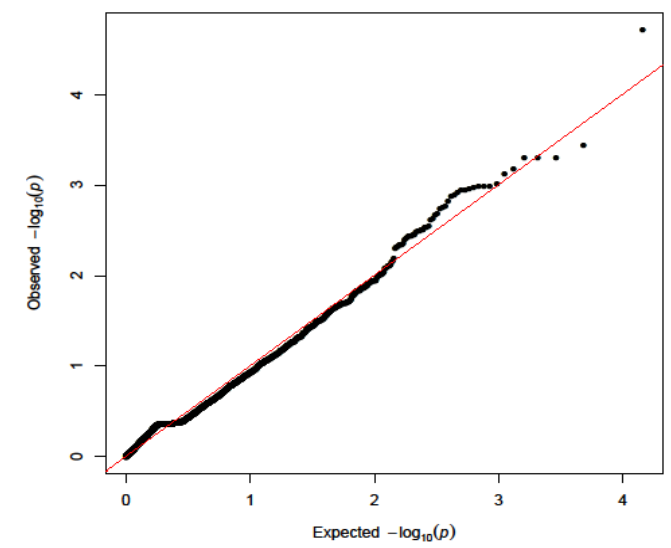

$\mathbf{a}$

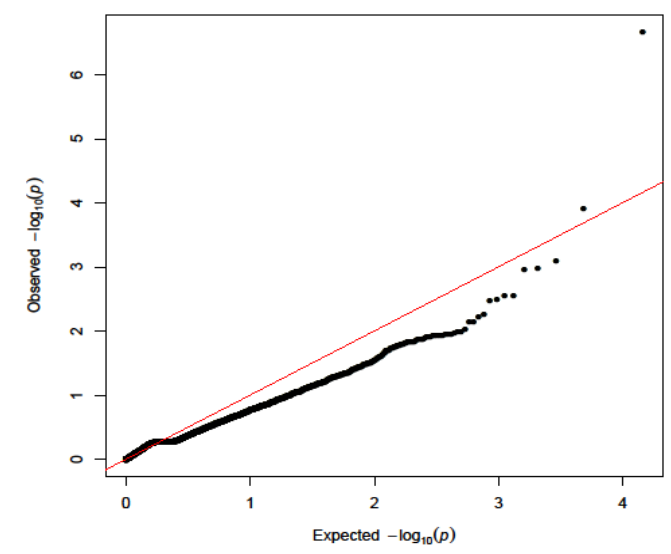

c

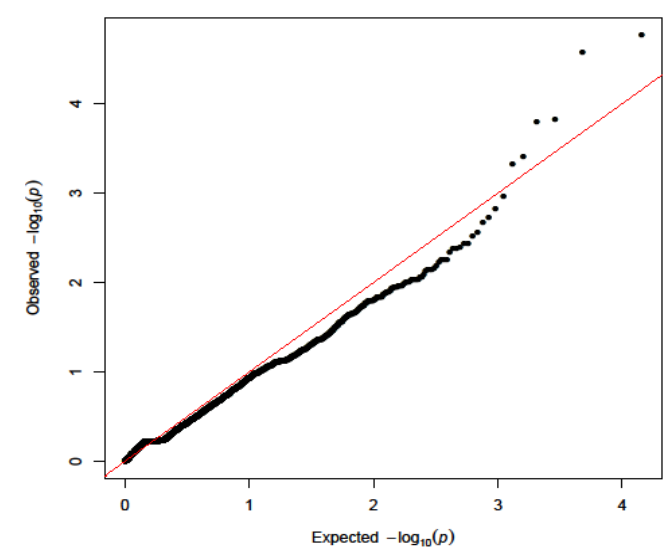

b

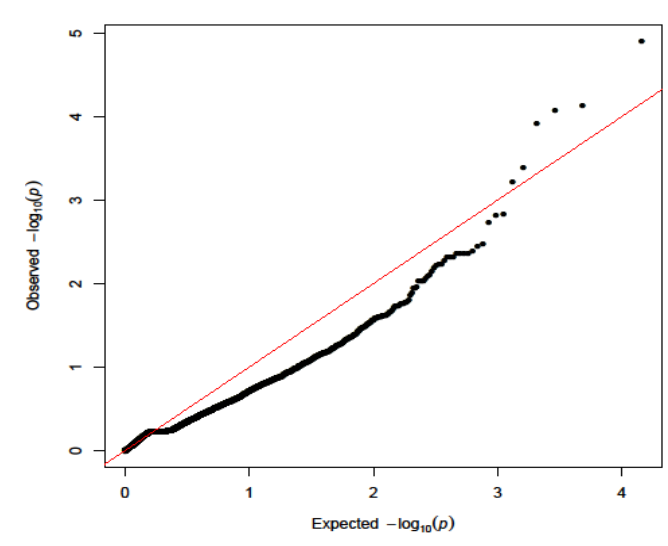

d 

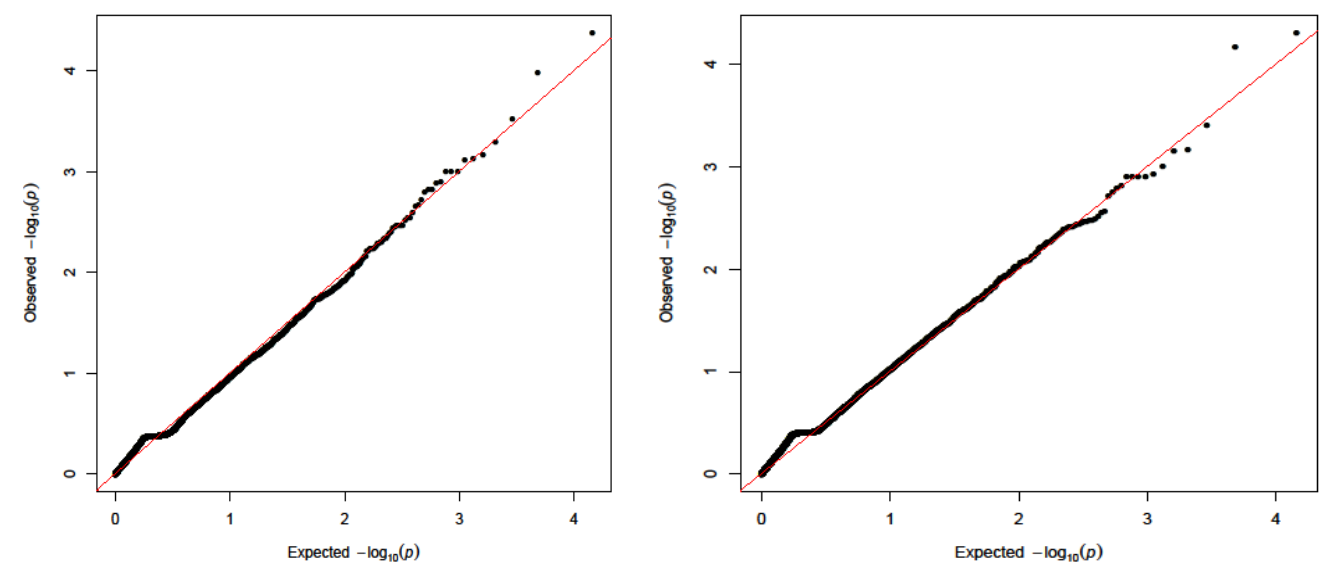

e

f
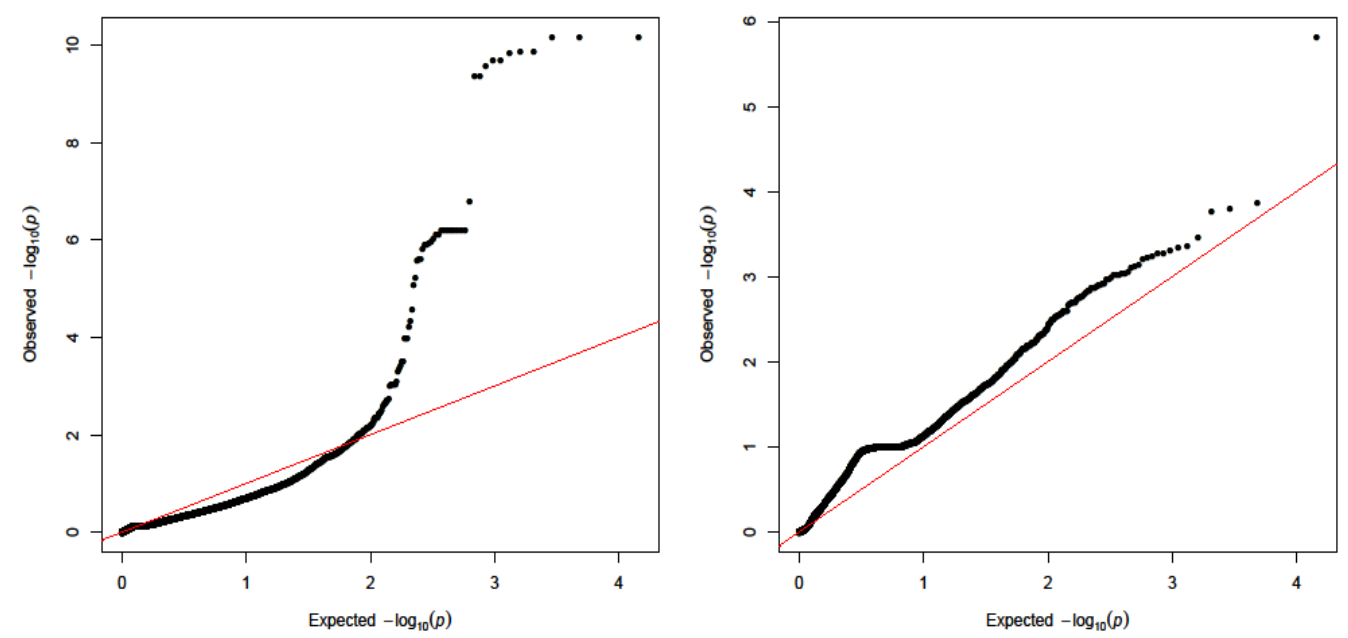

g

h
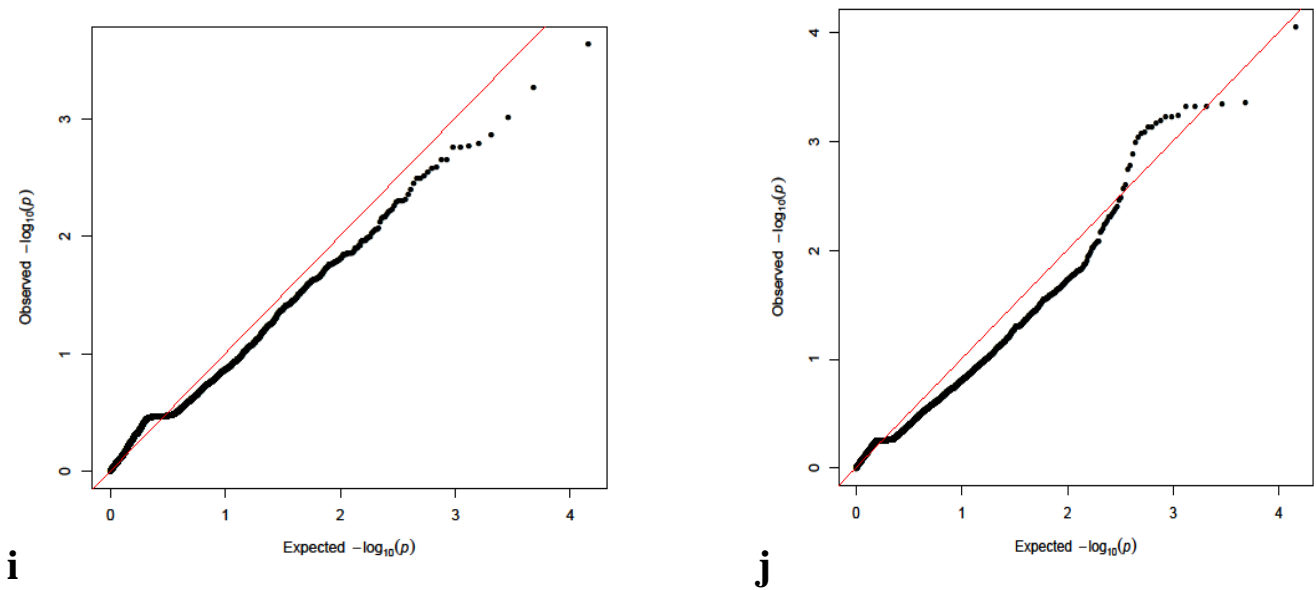

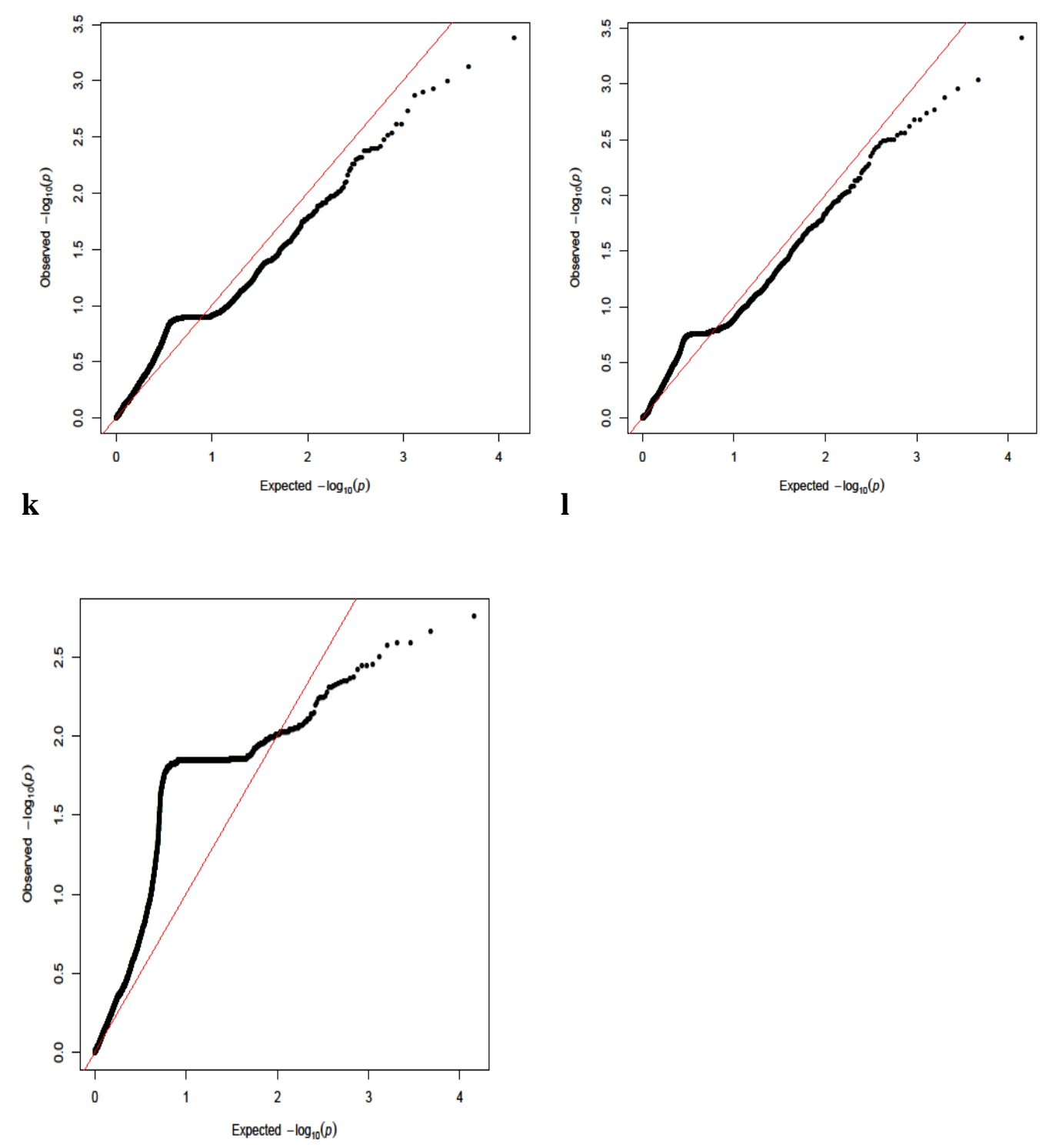

m

Figure 3: Q-Q plots showing the results of cowpea association mapping in glasshouse. The straight line in the Q-Q plot indicates the distribution of SNPs. a-AVSPD- average seeds per pod, b-DTE-days to emergence, $\mathbf{c}$-NP-number of pods, $\mathbf{d}$-number of seeds, e-PL-pod length, f-PWDTH-pod width, g-PWT-pod weight, h-RR-recovery rate, i-SC-survival count, $\mathbf{j}$ SWDT-seed weight, k-SGWK 3-stem greenness at 3 weeks after drought imposition, lWWK2-wilting at 2 weeks after drought imposition, m- WWK3-wilting at 3 weeks after drought imposition 


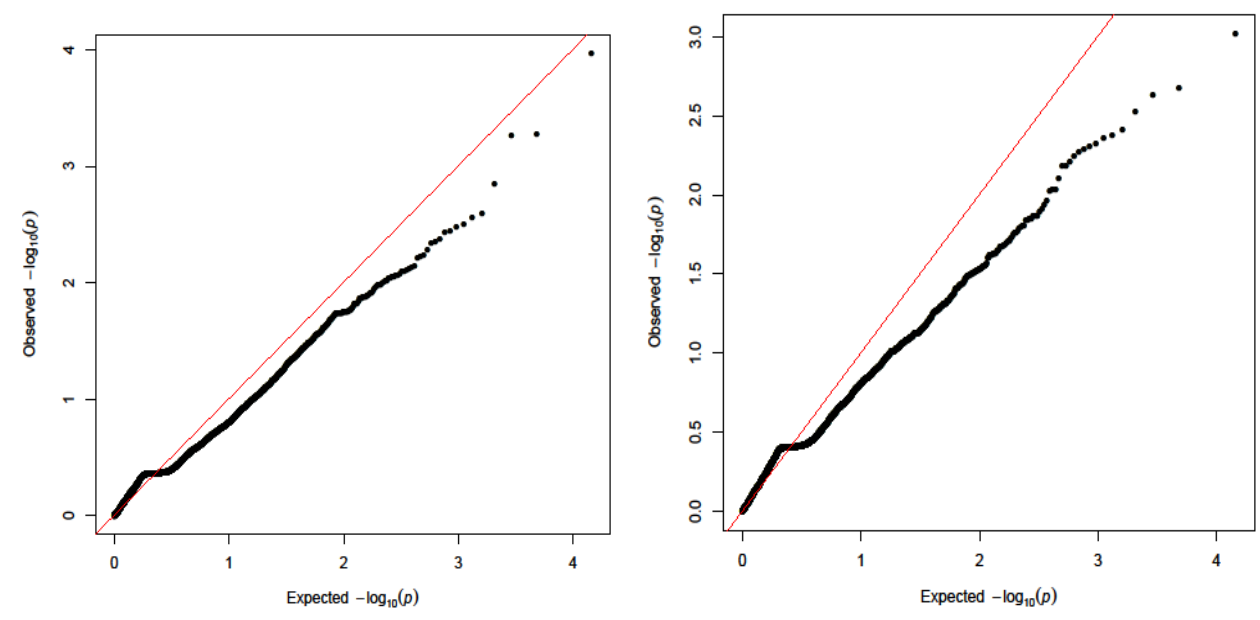

g

h
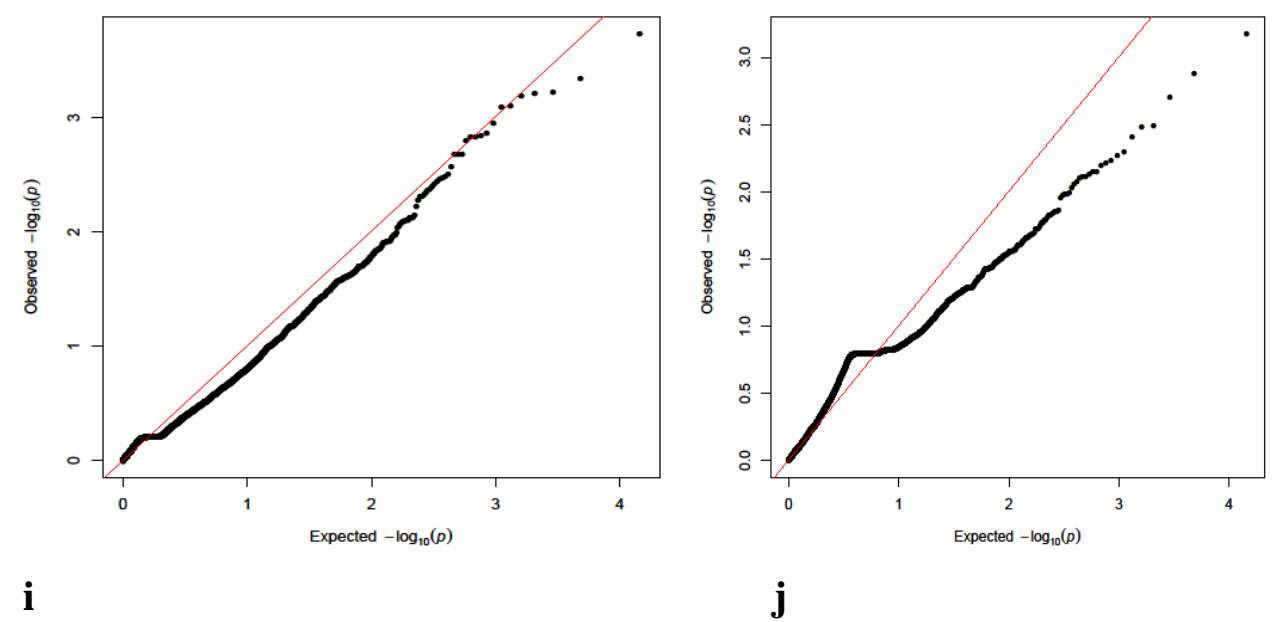

i 


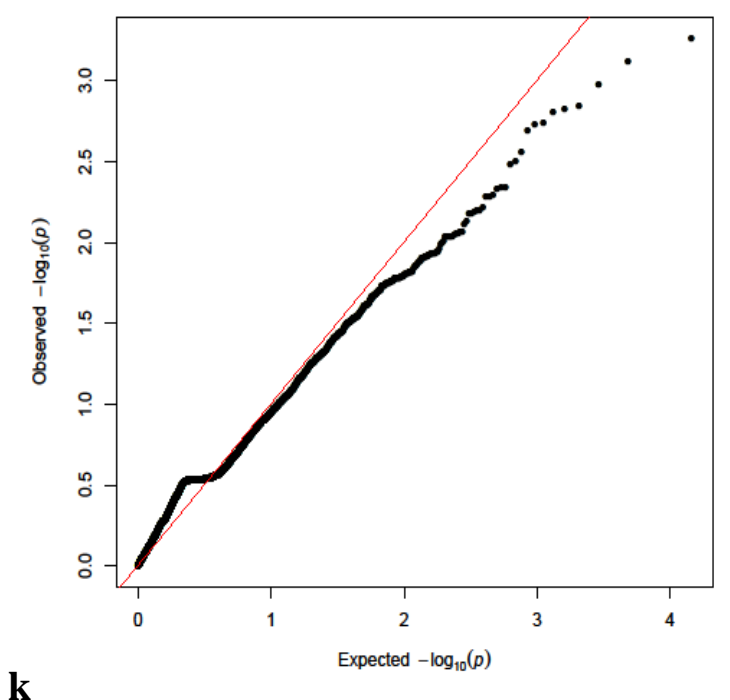

Figure 4: Q-Q plots showing the results of cowpea association mapping in greenhouse. The straight line in the Q-Q plot indicates the distribution of SNPs. a-AVSPD- average seeds per pod, b-NP-number of pods, c-NSDS-number of seeds, d-PL-pod length, e-PWDTH-pod width, f-PWT-pod weight, g-RR-recovery rate, $\mathbf{h}$-SC-survival count, i-SWDT-seed weight, $\mathbf{j}$ WWK2-wilting at 2 weeks after drought imposition, k- WWK3-wilting at 3 weeks after drought imposition

\section{Discussion}

The association mapping study provided an insight on the importance of traits that were useful in screening cowpea accessions at seedling level in a controlled environment. In both greenhouse and glasshouse experiments, variations were observed with regards to traits that were important in screening cowpea accessions at seedling stage. All the two experiments, however, pointed out that yield related traits are of utmost importance when selecting cowpea accession to drought tolerance at seedling stage. 
Population structure analysis revealed that 60 cowpea accessions can be divided into seven subpopulations, that is, population 1, population 2, population 3, population 4, population 5 , population 6 and population 7, from both screen houses. The population analysis showed that each subgroup is diverse from others. Populations 1 and 3 under greenhouse experiment and populations 2 and 5 in glasshouse experiment. These results would facilitate choices of parental lines in cowpea-breeding programs.

From the study chromosomes 1, 2, 3, 5, 6, 7, 8, 9, 10 and 11 have the most important genetic information and traits with regards to drought tolerance at seedling stage in the screen houses. Important traits such as NP, RR, AVSPD, PL, PWDTH and PWT were associated with different chromosomes with regards to drought tolerance. From this research PWT was the most important trait represented by 50 SNPs on nine different chromosome positions. Most of these positions were based in the glasshouse experiment. (18), observed that some marker performance indicators such as seed weight and seed number differ by environment. Pod formation and number of grains per pod depend on environmental factors before anthesis, while grain weight depend on environmental factors after anthesis (19). Thus the PWT trait was more pronounced in the glasshouse with more chromosomes exhibiting the trait than in the greenhouse. The study pointed out that these yield related traits are some of the important parameters to be used when selecting cowpea accessions for drought tolerance at seedling stage in screen houses. However, (20) observed that stem greenness, survival and recovery dry weights in greenhouse were the useful traits to screen cowpea genotypes for their ability to withstand drought stress at the seedling stage.

Under this study it was also observed that there was a strong co-location of SNP markers especially on chromosomes $1,3,5,6,7,8,9,10$ and 11 . SNP markers $100051488|\mathrm{~F}| 0-49$ and 
14083801|F|0-28 on chromosome 3 were associated with both AVSPD and PL. SNP marker 14083801|F|0-28 was also associated with PWDTH on chromosome 3. This suggests that drought tolerance traits are complex and these determines accurate measurements. (21), investigated candidate genes for seedling drought stress-induced premature senescence and observed seven markers co-located with peaks of previously identified QTL using restriction site polymorphisms. The co-location of these markers suggested that these markers were derived from genes which were involved in cowpea response to drought stress-induced premature senescence. (22), observed that when there is a smaller $p$ value, then that SNP marker is very ideal and should be validated for marker assisted selection (MAS).

Most of the trait-associated markers were different under the two screen houses, indicating the environmental effects in these associations (23). These results showed that different genes might contribute to the same trait in several environments (24) or there could be a change within the expression level of the same gene between two environments (25). Associated markers repeatedly detected in two or more different environments are considered more reliable than those present in just one environment (26). In this study, 2 markers showed stable association with different traits under both screen house conditions, notably markers $100051488|\mathrm{~F}| 0-49$ and $14083801|\mathrm{~F}| 0-28$. The detection of genomic regions associated with multiple traits across variable environments is essential in breeding crops for wide adaptation and yield stability (27).

Previous research has shown that plants with good drought tolerance at early vegetative growth were also able to withstand drought stress at a later stage of plant development (28). Drought tolerance is a complex phenomenon as it is controlled by many genes thus the use of more efficient tools like genomic selection (GS) for accelerated trait improvement is ideal (29). This 
is because during QTL analysis, (21), observed that the tolerant genotypes also contributed alleles that negatively influenced drought tolerance, and that the susceptible parent contributed alleles that enhanced drought tolerance. The use of SNP markers at seedling stage for drought tolerance can be a fast and cheaper way than the use of conventional breeding methods in a field environment.

\section{Conclusion}

The screening of cowpea accessions in a controlled environment is a fast way of evaluation, especially where temperature regulation is needed. Some variability in drought tolerancerelated traits among cowpea genotypes was observed in this study in both greenhouse and glasshouse experiments. The population structure analysis revealed that under that two screen houses there were seven subgroups although this was more pronounced in the greenhouse experiment. Drought tolerance in cowpea is controlled by multiple traits in cowpeas as was observed with SNPs100051488|F|0-49 and14083801|F|0-28. It is thus necessary to have accurate measurements of intended traits. In terms of drought tolerance at the seedling stage, various temperature regimes can be controlled; this can give desired results much quicker than field selection. The 65 SNP markers identified may be used in cowpea molecular breeding to select for AVSPD, NP, PL, PWDTH, PWT, and RR through MAS.

\section{Author Contributions:}

M.A.M. conceived the research while G.V.N. designed the research and conducted the experiment. R.P. analysed data. M.A.M. and M.M.S. supervised the manuscript G.V.N. wrote the manuscript. All authors read and approved the final manuscript. 


\section{Funding:}

This research was funded by Central University of Technology Free State, South Africa Research Grant Scheme.

\section{Acknowledgments}

The project was supported by the Central University of Technology, Free State Research Grant Scheme as well as Agriculture Research Council Grain Crops, Potchefstroom.

Conflicts of Interest: The authors declare no conflict of interest. The funders had no role in the design of the study; in the collection, analyses, or interpretation of data; in the writing of the manuscript, or in the decision to publish the results. 


\section{References}

1. Jayathilake, C.; Visvanathan, R.; Deen, A.; Bangamuwage, R; Jayawardana, B.C; Nammi, S.; Liyanage, R. Cowpea: An Overview on Its Nutritional Facts and Health Benefits. Journal of the Science of Food and Agriculture 2018. Volume 98. pp 4793-4806.doi: 10.1002/jsfa.9074.

2. Sharma, M.; Sharma, P.P.; Uphadhyay, B.; Bairwa, H.1. Study of Correlation Coefficient and Path Analysis in Cowpea [Vigna unguiculata (L.) Walp] Germplasm Line. International Journal of Development Research 2016 Volume 06 Issue, 08, pp. 9011-9016.

3. Agyeman, K.; Berchie, J.N.; Osei-Bonsu, I.; Tetteh, E.N.; Fordjour, K. Seed Yield and Agronomic Importance of Seven Improved Cowpea (Vigna unguiculata L) Varieties in Ghana. African Journal of Agricultural Research $2014 \quad$ Volume 10 pp 215221.doi:10.5897/AJAR2014.8835.

4. Menssena, M.; Lindeb, M.; Omondia, E.O.; Abukutsa-Onyango, M.; Dinssa, F.F.; Winkelmann, T. Genetic and Morphological Diversity of Cowpea (Vigna unguiculata (L.) Walp.) Entries from East Africa. Scientia Horticulturae 2017: 226 pp 268-276. https://doi.org/10.1016/j.scienta.2017.08.003.

5. Wang, L.; Bai, P.; Yuan, X.; Chen, H.; Wang, S.; Chen, X.; Cheng, X. Genetic Diversity Assessment of a Set of Introduced Mung Bean Accessions (Vigna radiata L.) The Crop Journal 2018:6:207 - 213. https://doi.org/10.1016/J.CJ.2017.08.004.

6. Abou-Elwafa, S.F. 2016. Association Mapping for Drought Tolerance in Barley at the Reproductive Stage. Comptes Rendus Biologies 2016:339:51-59.

7. Ballesta, P.; Mora, F.; Del Poz, A. Association Mapping of Drought Tolerance Indices in Wheat: QTL-Rich Regions on Chromosome 4A. Scientia Agricola 2019:77(2) e20180153.https://dx.doi.org/10.1590/1678-992x-2018-0153. 
8. Kouam, E.B.; Ngompe-Deffo, T.; Anoumaa, M.; Pasquet, R.S.; Preliminary Study on Character Associations, Phenotypic and Genotypic Divergence for Yield and Related Quantitative Traits among Cowpea Landraces (Vigna unguiculata) from the Western Highland Region of Cameroon. Open Agriculture 2018: 3: 84-97. https://doi.org/10.1515/opag-20180009.

9. Benjamin, U.; Olamide, F.; Yusuf, D.O.A.; Abdulhakeem, A.; Junior, N.D.; David, T.S; Muhammad, M.L. Phenotypic Variability Studies in Selected Accessions of Nigerian Wild Cowpea (Vigna unguiculata L. Walp) GSC Biological and Pharmaceutical Sciences 2018: 03: 019-027. https://doi.org/10.30574/gscbps.2018.3.1.0015.

10. Qin, J.; Shi, A.; Xiong, H.; Mou, B.; Motes, D.; Lu, W.; Miller Jr W.J.C.; Scheuring, D.C.; Nzaramba, M.N.; Weng, Y.; Yang, W. Population Structure Analysis and Association Mapping of Seed Antioxidant Content in USDA Cowpea (Vigna unguiculata L. Walp.) Core Collection Using SNPs. Canadian Journal of Plant Science 2016: 96: 10261036.https://doi.org/10.1139/cjps-2016-0090.

11. Xu, P.; Wu, X.; Muñoz-Amatriaín, M.; Wang, B.; Wu, X.; Hu, Y.; Huynh, B.L.; Close, T.J.; Roberts, P.A.; Zhou, W.; Lu, Z.; Li, G. Genomic Regions, Cellular Components and Gene Regulatory Basis Underlying Pod Length Variations in Cowpea (Vigna. unguiculata L. Walp). Plant Biotechnology Journal 2017:15:547-557. doi:10.1111/Pbi.12639.

12. Ravelombola, W.; Shi, A.; Weng, Y.; Mou, B.; Motes, D.; Clark, J.; Chen, P.; Srivastava, V.; Qin, J.; Dong, L.; Yang, W.; Bhattarai, G.; Sugihara, Y. Association Analysis of Salt Tolerance in Cowpea (Vigna unguiculata (L.) Walp) At Germination and Seedling Stages. Theoretical and Applied Genetics 2017 Volume 131, Issue 1, pp 79-91. doi: 10.1007/s00122-017-2987-0.

13. Doyle, J.J.; Doyle, J.L. A rapid DNA isolation procedure for small quantities of fresh leaf tissue. Phytochemical Bulletin 1987 v.19, p.11-1.

14. Pritchard, J.K.; Stephens, M.; Donnelly, P. Inference of Population Structure Using Multilocus Genotype Data. Genetics 2001: 155:945-959. 
15. Evanno, G.; Reganut, E.; Goudet, J. Detecting the Number of Clusters of Individuals Using the Software STRUCTURE: A Simulation Study. Molecular Ecology Notes 2005: 14: 26112620.

16. Earl, D.A.; Von Holdt B.M. STRUCTURE HARVESTER: A website and Program for Visualizing STRUCTURE Output and Implementing the Evanno Method. Conservation Genetic Resources 2011: 4:359-361.

17. Bradbury, P.J.; Zhang, Z.; Kroon, D.E.; Casstevens, T.M.; Ramdoss, Y.; Buckler, E.S. TASSEL: Software for Association Mapping of Complex Traits in Diverse Samples. Bioinformatics 2007: 23:2633-2635.

18. Burridge, J.D.; Schneider, H.M.; Huynh, B.L.; Roberts, P.A.; Bucksch, A.; Lync, J.P. Genome-Wide Association Mapping and Agronomic Impact of Cowpea Root Architecture. Theoretical and Applied Genetics 2016. doi 10.1007/s00122-016-2823-y.

19. Freitas, T.G.G.; Silva, P.S.L.; Dovale, J.C.; Silva, I.N.; Silva, E.M. Grain Yield and Path Analysis in the Evaluation of Cowpea Landraces. Revista Caatinga 2019:32(2), 302311.https://doi.org/10.1590/1983-1252019v32n202rc.

20. Muchero, W.; Ehlers, J.D.; Roberts, P.A. Seedling Stage Drought-Induced Phenotypes and Drought-Responsive Genes in Diverse Cowpea Genotypes. Crop Science 2008:48:541-552.

21. Muchero, W.; Ehlers, J.D.; Roberts, P.A. Restriction Site Polymorphism-Based Candidate Gene Mapping for Seedling Drought Tolerance in Cowpea [Vigna unguiculata (L.) Walp.]. Theoretical and Applied Genetics 2009: 120(3):509-518. doi: 10.1007/s00122-009-1171-6.

22. Chitwood, J.; Shi, A.; Evans, M.; Clark, J.; Motes, D.; Chen, P.; Hensley, D. Population Structure and Association Analysis of Bolting, Plant Height, and Leaf Erectness in Spinach. Hortscience 2016: 51(5):481-486.

23. Baye, T.M.; Abebe, T.; Wilke, R.A. Genotype-Environment Interactions and Their Translational Implications. Personalised Medicine 2011 8(1):59-70. doi:10.2217/pme.10.75. 
24. Rumbaugh, M.D.; Asay, K.H.; Johnson, D.A. Influence of Drought Stress on Genetic Variance of Alfalfa and Wheat Grass Seedling. Crop Science 1984: 24: 297-303. doi:10.2135/cropsci1984.0011183X0024000 20021x.

25. House, M.A.; Griswold, C.K.; Lukens, L.N. Evidence for Selection on Gene Expression in Cultivated Rice (Oryza sativa). Molecular Biology and Evolution 2014: 31: 1514-1525. doi:10.1093/molbev/msu110.

26. Diapari, M.; Sindhu, A.; Warkentin, T.D.; Bett, K.; Tar'an, B. Population Structure and Marker-Trait Association Studies of Iron, Zinc and Selenium Concentrations in Seed of Field Pea (Pisum sativum L.). Molecular Breeding 2015:35: 30. doi:10.1007/s11032-015-0252-2.

27. Saeed, I.; Chen, X.; Bachir, D.G.; Chen, L.; Hu, Y.G. Association Mapping for Photosynthesis and Yield Traits under Two Moisture Conditions and Their Drought Indices in Winter Bread Wheat (Triticum aestivum L.) Using SSR Markers. Australian Journal of Crop Science 2017: 11: 248-257. doi:10.21475/ajcs.17.11.03. pne252.

28. Tomar, R.S.; Tiwari, S.; Naik, B.K.; Chand, S.; Deshmukh, R.; Mallick, N.; Singh, S.; Singh, N.K.; Tomar, S.M. Molecular and Morpho-Agronomical Characterization of Root Architecture at Seedling and Reproductive Stages for Drought Tolerance in Wheat. PLoS One 2016 :11(6): e0156528.

29. Jha, U.C.; Bohra, A.; Nayyar, H. Advances in Omics Approaches to Tackle Drought Stress in Grain Legumes. Plant Breeding 2020: 139:1-27. https://doi.org/10.1111.pbr.12761. 